\title{
Alpha-Aminoadipic Acid
}

National Cancer Institute

\section{Source}

National Cancer Institute. Alpha-Aminoadipic Acid. NCI Thesaurus. Code C118881.

An alpha-amino acid that is an intermediate in the lysine degradation pathway. It is

synthesized from homoisocitrate and then converted to a semialdehyde that reacts with glutamic acid to form saccharopine. Alpha-aminoadipic acid levels are elevated in tissues of certain cancers and may potentially be used as a cancer biomarker. 